\title{
1 Social boldness correlates with brain gene expression in male green
}

\section{anoles}

5 'Department of Biology \& Program in Neuroscience, Rhodes College, Memphis TN 38112 USA

8 Key words: RNAseq, boldness, secretin, androgen, calcium channel, ventromedial

9 hypothalamus, reptile, lizard, integrin alpha-10, steroid hormones

11 * Please send correspondence to:

12 David Kabelik

13 Department of Biology

14 Rhodes College

152000 N Parkway

16 Memphis, TN 38112

17 USA

18 kabelikd@rhodes.edu

19 901-843-3699 (phone)

$20901-843-3565$ (fax) 


\section{Abstract}

Within populations, some individuals tend to exhibit a bold or shy social behavior

24 phenotype relative to the mean. The neural underpinnings of these differing phenotypes - also

25 described as syndromes, personalities, and coping styles - is an area of ongoing investigation.

26 Although a social decision-making network has been described across vertebrate taxa, most

27 studies examining activity within this network do so in relation to exhibited differences in

28 behavioral expression. Our study instead focuses on constitutive gene expression in bold and shy individuals by isolating baseline gene expression profiles that influence social boldness predisposition, rather than those reflecting the results of social interaction and behavioral execution. We performed this study on male green anole lizards (Anolis carolinensis), an established model organism for behavioral research, which provides a crucial comparison group to investigations of birds and mammals. After identifying subjects as bold or shy through repeated reproductive and agonistic behavior testing, we used RNA sequencing to compare gene expression profiles between these groups within various forebrain, midbrain, and hindbrain regions. The ventromedial hypothalamus had the largest group differences in gene expression,

37 with bold males having increased expression of neuroendocrine and neurotransmitter receptor

38 and calcium channel genes compared to shy males. Conversely, shy males express more

39 integrin alpha-10 in the majority of examined regions. There were no significant group

40 differences in physiology or hormone levels. Our results highlight the ventromedial

41 hypothalamus as an important center of behavioral differences across individuals and provide

42 novel candidates for investigations into the regulation of individual variation in social behavior 43 phenotype. 


\section{Introduction}

Individuals vary widely in their social boldness. Some individuals perform many high intensity behaviors within moments of participating in a novel social encounter, while others hesitantly engage in a few low-intensity interactions. Often, such social boldness is consistent across different social environments, and correlates with other behavioral traits like active versus passive stress coping (Coppens et al., 2010; Koolhaas et al., 2010; Stamps and Groothuis, 2010). Although a continuum of such behavioral propensity usually exists within a population, we can categorize individuals at each end of such a continuum as either behaviorally 'bold' or 'shy', with bold individuals exhibiting lower latency, higher frequency, and higher intensity of exhibited social behaviors across contexts than shy individuals. Such behavioral phenotypes, also referred to as behavioral syndromes, personalities, or coping styles (Koolhaas et al., 2010; Réale et al., 2010; Sih et al., 2004), often manifest as correlated suites of behavioral outputs, presumably due in part to regulation by shared neural underpinnings. The neural substrates that lead an individual toward exhibiting a bold or shy phenotype likely rely on brain regions involved in social decision-making (Newman, 1999; O'Connell and Hofmann, 2012, 2011) and neuroendocrine mediators of these circuits (Baugh et al., 2012; Félix et al., 2020; Ketterson and Nolan Val, 1999). Although numerous neural systems have been associated with social behavioral output, the specific proximate variables that determine stable bold-shy behavioral phenotypes remain unknown. Understanding how the brain regulates social behavior propensity is both fundamentally intriguing and also necessary to address various disorders involving social anxiety, depression, and aggression.

Among vertebrates, the lack of understanding of neuroendocrine regulators of behavioral phenotypes is especially true among non-avian reptiles, as they are the least studied vertebrate taxonomic group (Kabelik and Hofmann, 2018), despite serving as an important evolutionary comparison group, especially for amniotic vertebrates. A social decision-making network has 
been described in reptiles (Kabelik et al., 2018), and various neuroendocrine variables have been related to the expression of social behaviors in lizards (Dunham and Wilczynski, 2014; Hartline et al., 2017; Kabelik et al., 2013, 2008b; Kabelik and Crews, 2017; Kabelik and Magruder, 2014; Korzan et al., 2001; Korzan and Summers, 2004; Larson and Summers, 2001; Smith and Kabelik, 2017; Watt et al., 2007; Woolley et al., 2004a, 2004b, 2001). However, many potential neural, endocrine, and direct genetic regulators of social boldness remain unexamined. In this study, we compare gene expression from various brain regions of male green anoles (Anolis carolinensis) that exhibit either stable bold or shy phenotypes in order to identify potential regulatory variables. Green anoles are a longstanding model for social behavior investigation (Lovern et al., 2004), and they have recently become a model for comparative genomic investigation (Alföldi et al., 2011), making them an ideal subject species for the present boldness within both contexts.

Many studies of social boldness examine gene expression resulting from the performance of specific social behaviors (e.g., Mukai et al., 2009; Wong et al., 2012; Zayed \& Robinson, 2012), or by adoption of a dominant or submissive status within a social hierarchy (e.g., Eastman et al., 2020; Renn et al., 2008). Here we instead examine differences in baseline expression differences associated with expressed behavioral output and instead places focus on the neural state differences that may be associated with consistent bold or shy behavioral

91 outputs outside of behavioral encounters with conspecifics. Additionally, the examined males are housed individually and thus hold identical home 'territories', eliminating social status- 
analysis and compared gene expression profiles between these experimental groups across

95 several brain regions.

As bold and shy behavioral traits have been associated with brain regions governing social behavior in other taxa (Delclos et al., 2020; Geng and Peterson, 2019; Koolhaas et al., 2010), we examined gene expression in four forebrain, one midbrain, and one hindbrain region of the social behavior network. The examined brain regions include nodes of the social decisionmaking network, such as the preoptic area, lateral septum, and ventromedial hypothalamus of the forebrain, as well as the ventral tegmental area of the midbrain. Additional regions that we sampled included the medial and dorsomedial cortex, which are considered at least partly homologous to the mammalian hippocampal complex (Desfilis et al., 2018; Striedter, 2016; Tosches et al., 2018), and the dorsal ventricular ridge, an area partly homologous and partly analogous to the mammalian neocortex (Briscoe et al., 2018; Briscoe and Ragsdale, 2018; Colquitt et al., 2021; Northcutt, 1981) and amygdaloid nuclei (Lanuza, 1998; Martínez-García et al., 2002). Finally, a rostral hindbrain region was also examined, as the hindbrain has also been linked to the regulation of social behaviors (Thompson et al., 2008; Walton et al., 2010). We tested the hypothesis that bold and shy male green anoles would differ in sex steroid hormone levels and gene expression, with an emphasis on hypothalamic regions.

\section{Materials and Methods}

\section{Subjects}

Fifty-seven focal male green anoles (Anolis carolinensis) were obtained from a commercial supplier. These males were housed singly within terraria $(30.5 \mathrm{~cm} \mathrm{H}$ x $26 \mathrm{~cm} \mathrm{~W} \mathrm{x}$ $51 \mathrm{~cm} \mathrm{~L}$ ) and kept in breeding season conditions: long-day (14 light:10 dark) full-spectrum lighting, 12 hours of supplemental heat provided $5 \mathrm{~cm}$ above one end of a wire-mesh terrarium 
lid by means of a 60-W incandescent light bulb, and thrice-weekly feeding with crickets. Additional males and females from our housing colony were used in social interactions. All procedures involving live animals were conducted according to federal regulations and approved by the Institutional Animal Care and Use Committee at Rhodes College.

\section{Social behavior boldness assessment}

Behavioral trials were carried out from May 14 to July 3, 2013. Focal males were each assessed three times with different conspecifics for social boldness within each of three social encounter scenarios - reproductive encounter, agonistic encounter as a resident, and agonistic encounter as an intruder. Thus, each focal male's behavior was scored in nine separate 10-min behavioral encounters, and a maximum of one social encounter per focal male was run per day. The reproductive behavior scenario involved two conspecific adult females simultaneously placed into the focal male's terrarium. Two females were used to maximize the probability of eliciting reproductive behaviors from the focal male. We recorded the frequency (sum of behaviors per 10-min session) and latency to first performance (minute of first occurrence of any listed behavior) of the following behaviors: head bob bout, push-up bout, dewlap extension bout, dewlap extension bout with push up, chase, and copulate. Focal males that failed to display any behaviors were assigned the maximum latency score of $10 \mathrm{~min}$. The maximum intensity of behavioral display was also scored from 0-3 based on the highest achieved category: no display, display only, chase, and copulate. The agonistic encounter as a resident scenario involved a size-matched (within $3 \mathrm{~mm}$ snout-vent length) adult conspecific male intruder being placed within the focal male's terrarium. Behaviors were scored as in the reproductive encounter, except that biting of the stimulus male replaced copulation as the highest intensity behavior. The agonistic encounter as an intruder scenario involved the focal male being taken out of his terrarium and placed into the terrarium (home territory) of a size-matched adult 
143

144

145

146

147

conspecific male. Behavioral scoring was the same as in the previous agonistic scenario. Stimulus animals were also only used once per day, and no behavioral trials involved the repeated pairing of the same subjects.

\section{Bold-shy categorization}

We conducted principal components analysis (PCA) using SPSS Statistics 22 (IBM) to reduce the average behavioral latency, frequency, and intensity scores from each of the three social behavior interaction scenarios into a single value. For example, in male-female trials, the behavioral latency, frequency, and intensity scores for each male were averaged across the three trials in which he took part, in order to generate an "average reproductive latency", "average reproductive frequency", and "average reproductive intensity" score. These average scores were then included in the PCA. In each scenario, the resulting analysis generated a single PCA axis with an eigenvalue $>1$, and in each case, this axis was highly positively correlated with average frequency and intensity scores, and negatively with average latency scores ( $r> \pm 0.73, p<0.001$ for each). This PCA axis 1 explained $65 \%$ of the behavioral variation in the reproductive boldness trial, $79 \%$ of the variation in the agonistic trial as resident, and $80 \%$ of the variation in the agonistic trial as intruder (see the supplementary materials for scree plots and loading tables). We used these PCA axes to correlate boldness across behavioral scenarios. We also took an average of these three PCA axes to use in selecting bold and shy individuals for the RNAseq portion of this study. Because the average PCA axis 1 score differed across the three behavioral testing blocks $(F(2,54)=4.23, p=0.02)$, we ranked focal males based on this average PCA principal component axis 1 score within each behavioral block. We then chose the highest and lowest scoring focal male within each block, as well as the next highest and next lowest scoring focal male in two of the three blocks. This resulted in selection of the five most socially 'bold' and five most 'shy' males out of the 57 focal males screened for 
168

169

170

171

172

173

174

175

176

177

178

179

180

181

182

183

184

185

186

187

188

189

190

191

192

behavioral consistency. Scatterplots of PCA scores were made with ggplot2 (version 3.3.0) in RStudio (version 1.3.1056) running $R$ (version 3.5.2).

Tissue harvesting and brain tissue punching

Prior to handling for blood and brain harvesting, focal subjects were left undisturbed in their home terraria for 1-3 days following their last behavioral trial. We euthanized focal males by cutting through the spinal column and immediately collected trunk blood for hormone analyses (average collection time from first handling was $162 \pm 3.2 \mathrm{~s}$ ). The blood was kept at $4^{\circ} \mathrm{C}$ until centrifugation. The brain was then rapidly dissected, placed within a microcentrifuge tube filled with Tissue Tek (Sakura) cutting medium, and frozen under dry ice (average time from first handling to freezing of brain was $544 \pm 8.4 \mathrm{~s}$ ). The body (minus the head and some blood) was then weighed, after which the testes were dissected from the body and also weighed. Brains were sectioned at $100 \mu \mathrm{m}$ on a Microm HM 520 cryostat (Thermo Scientific). The sections were laid onto glass microscope slides resting on a metal block within the cryostat at $-19^{\circ} \mathrm{C}$. Tissue punches of selected areas were obtained using a Stoelting brain punch set with the aid of a dissecting microscope (Olympus SZX7) mounted above the cryostat. Brain punches were placed into Trizol (Invitrogen) and frozen at $-80^{\circ} \mathrm{C}$. Either $1 \mathrm{~mm}$ or $1.25 \mathrm{~mm}$ tissue punches were used to obtain tissue from selected brain regions (see Supplementary Figure 1 for brain punch locations). These brain punch locations were as follows: POA-LS, a region including the preoptic area, anterior hypothalamus, paraventricular nucleus of the hypothalamus, and septal nuclei; HIP, a region of the medial and dorsomedial cortices, which are at least partly homologous to the mammalian hippocampus (Desfilis et al., 2018; Striedter, 2016; Tosches et al., 2018); DVR, including the subcortical pallium (dorsal ventricular ridge, including amygdaloid nuclei) as well as striatum; $\mathrm{VMH}$, the ventromedial hypothalamus; MID, the midbrain tegmentum; HIND, the pons and rostral medulla, though not cerebellum. Brain regions were 
193

194

195

196

197

198

determined by reference to multiple atlases and publications (Bruce and Braford, 2009; Butler and Hodos, 2005; Greenberg, 1982; Hoops et al., 2018; Jarvis, 2008; Kabelik et al., 2014; Lopez et al., 1992; Naik et al., 1981; O'Connell and Hofmann, 2011; Rosen et al., 2002; ten Donkelaar, 1998).

\section{Hormone analyses}

Blood samples were centrifuged and plasma (averaging $77 \pm 3.3 \mu \mathrm{l}$ ) was frozen at $-80^{\circ} \mathrm{C}$ until hormone analysis. We quantified testosterone (ADI-900-065; sensitivity $5.67 \mathrm{pg} / \mathrm{mL}$ ), estradiol (ADI-900-008; sensitivity 28.5 pg/mL), progesterone (ADI-900-011; sensitivity 8.57 $\mathrm{pg} / \mathrm{mL}$ ), and cortisol (ADI-900-071; sensitivity $56.72 \mathrm{pg} / \mathrm{mL}$ ) using enzyme-linked immunosorbent assay (ELISA) kits (Enzo Life Sciences, Farmingdale, NY). The cortisol kit cross-reacts with corticosterone at $28 \%$, representing a general glucocorticoid assay, albeit with lower-than-typical sensitivity. Samples were run across two plates for each hormone and the inter-assay variation across plates and the intra-assay variance for each plate is as follows: testosterone (inter: 5.6\%; intra: 5.6\% and 6.1\%), estradiol (inter: $4.1 \%$; intra: $3.7 \%$ and $8.5 \%$ ), progesterone (inter: 4.7\%; intra: $2.3 \%$ and $4.7 \%$ ), and cortisol (inter: $6.4 \%$; intra: $3.8 \%$ for both plates). We re-suspended $7 \mu \mathrm{l}$ of plasma in $203 \mu \mathrm{L}$ of the appropriate assay buffer and ran each sample in duplicate as per manufacturer's instructions. Hormone results were generally consistent with previously reported levels in this species (Greenberg and Crews, 1990).

\section{RNA sequencing and analyses}

Brain RNA was extracted using Trizol according to manufacturer's instructions (Thermo Fisher Scientific). Poly-adenylated RNA was isolated from each sample using the NEXTflex PolyA Beads purification kit (Perkin Elmer). Strand-specific libraries with unique barcodes were 
217 prepared using the NEXTFLEX Rapid Directional RNA-Seq kit 2.0 according to manufacturer's

218 instructions (Perkin Elmer). Libraries were pooled in equal molar amounts and sequenced on an

219 Illumina HiSeq 2500 to obtain roughly 40 million reads per sample.

220

221 (http://www.bioinformatics.babraham.ac.uk/projects/trim galore/; parameters: trim_galore --

We first applied quality and adaptor trimming to the raw reads using Trim Galor!

222 paired --phred33 --length 36 -q 5 --stringency 5 --illumina -e 0.1). Reads were then aligned

223 using kallisto (Bray et al., 2016) with default parameters to the Anolis carolinensis cDNA

224 reference transcriptome (Anolis_carolinensis.AnoCar2.0.cdna.all.fa.gz) downloaded from

225 Ensembl (May 2020). Read counts were combined into a single matrix. Differences in gene

226 expression within each brain region were calculated using DESeq2 (Love et al., 2014) within the

227 in silico Trinity pipeline ( $p<0.05$, 4-fold change). We corrected $p$-values for multiple hypothesis

228 testing and considered transcripts with false discovery rate (FDR) correct p-values $<0.05$

229 significantly differentially expressed. We performed a gene ontology enrichment analysis for

230 differentially expressed genes in the ventromedial hypothalamus using the PANTHER (version

231 14; http://pantherdb.org/; Mi et al., 2019). Data visualizations were made in RStudio (version

232 1.3.1056) running $R$ (version 3.5.2). The PCA analysis for gene expression was performed

233 using the prcomp function in the $\mathrm{R}$ base package on normalized gene counts and the PCA was

234 plotted using the fviz_pca_ind function in factoextra (version 1.0.7). We tested for brain region

235 and behavioral group differences in principal components using the aov function in the $\mathrm{R}$ base

236 package. Boxplots and bar charts were made with ggplot2 (version 3.3.0), the volcano plots

237 were generated using EnhancedVolcano (version 1.0.1), and the heatmap was generated with

238 heatmap.2 function in gplots (version 3.1.1). 
Some behavioral scores and all hormone levels were In-transformed to meet

242 assumptions of parametric analyses. Data reduction was conducted using PCA, and the

243 comparison of the average resultant score across behavioral testing blocks was conducted

244 using one-way analysis of variance. Correlations among behavioral scores were conducted

245 using Pearson's r. Behavioral and physical differences between bold and shy focal males were

246 examined via independent-samples t-tests, except for behavioral intensity measure, which was

247 compared using a Mann-Whitney $U$ test. Analysis of gene expression of candidate genes from

248 the literature was performed by obtaining the normalized gene expression for each gene and

249 using a linear mixed model in R (Imer function in the Ime4 package, version 1.1-21) to test for

250 differences among behavioral group, brain regions, and their interaction with individual as a

251 random effect to account for repeated sampling of brain regions from the same lizards.

252 Significant differences were then followed up with pairwise comparisons in $\mathrm{R}$ using emmeans

253 (version 1.4.6), which adjusts for multiple comparisons.

255 Results

Correlated behavioral traits are stable within individuals

Individual differences in social boldness are relatively stable across different types of

258 social encounters. In Figure 1, we present correlations between focal males in the reproductive,

259 agonistic as a resident, and agonistic as an intruder scenario, reflecting latency, frequency, and

260 intensity measures reduced into a single principal component axis for each scenario. We found

261 positive correlations between boldness scores across all behavioral scenarios: reproductive

262 boldness and boldness as the resident in an agonistic trial $(r=0.55, N=57, p<0.001)$, between

263 boldness as the resident in an agonistic trial and boldness as the intruder in an agonistic trial 
264

265

266

267

268

269

270

271

272

273

274

275

276

277

278

279

280

281

282

283

284

285

286

$(r=0.50, N=57, p<0.001)$, and between reproductive boldness and boldness as the intruder in an agonistic trial $(r=0.29, N=57, p=0.026)$.

\section{Behavioral, but not physiological, traits differ between bold and shy individuals}

Relative to shy males, the bold males showed a higher average frequency of reproductive behaviors, agonistic behaviors as a resident, and agonistic behaviors as an

intruder (Table 1). Similarly, the bold males exhibited lower average latencies to first reproductive behavior, to first agonistic behavior as a resident, and to first agonistic behavior as an intruder. Bold males also exhibited higher average behavioral intensities to females, as resident males in agonistic trials, and as intruder males in agonistic trials. These results confirm that our categorization of subjects as bold or shy effectively discriminated individuals upon all three boldness measures (latency, frequency, and intensity). However, behavioral boldness was not correlated with physical ( $p \geq 0.10$ for all) or hormonal ( $p \geq 0.28$ for all) characteristics across all 57 males, nor between bold and shy groupings (Table 1). Bold and shy focal males did not differ in snout-vent length, or body-minus-head mass (the body was weighed after blood sampling and brain removal, so as not to delay freezing of brain tissue). Likewise, these groups did not differ in testes mass, or in circulating testosterone, estradiol, progesterone, or glucocorticoid levels.

Table 1. Mean and standard error (S.E.) values for behavioral and physical variables of bold and shy male green anoles. No physical but all behavioral variables differ between bold and shy groups. Parametric comparisons state the t statistic $(\mathrm{t})$ and degrees of freedom (df); nonparametric comparisons state the $U$ statistic $(U)$ and the sample size $(\mathrm{N})$; both state the probability of significance $(P)$ at $\alpha=0.05$.

\section{Shy Shy Bold Bold $t / U$ Df/N mean S.E. mean S.E.}

Behavioral Variables:

$\begin{array}{lllllll}11.1 & 2.62 & 27.9 & 1.72 & -5.36 & 8 & \mathbf{0 . 0 0 1}\end{array}$

(\#/10 min)

resident agonistic frequency

$4.3 \quad 2.86$

38.4

6.08

$-5.07$

$8 \quad 0.001$ 
intruder agonistic frequency

(\#/10 min)

reproductive behavior latency

(min)

resident agonistic latency (min)

intruder agonistic latency ( $\mathrm{min})$

reproductive behavior intensity

(0-3 scale)

resident agonistic intensity $(0-3$

scale)

intruder agonistic intensity $(0-3$

scale) $\begin{array}{lllllll}7.7 & 2.71 & 32.3 & 3.58 & -5.50 & 8 & \mathbf{0 . 0 0 1}\end{array}$

$\begin{array}{lllllll}3.7 & 0.80 & 1.1 & 0.06 & 3.44 & 8 & 0.009\end{array}$

$\begin{array}{lllllll}6.9 & 1.07 & 1.0 & 0.00 & 10.36 & 8 & <0.001\end{array}$

$\begin{array}{lllllll}7.6 & 0.81 & 1.6 & 0.24 & 7.13 & 8 & <0.001\end{array}$

$\begin{array}{lllllll}0.9 & 0.07 & 1.5 & 0.17 & 1.50 & 10 & \mathbf{0 . 0 1 6}\end{array}$

$\begin{array}{lllllll}0.7 & 0.35 & 2.3 & 0.29 & 1.50 & 10 & \mathbf{0 . 0 1 6}\end{array}$

$\begin{array}{lllllll}0.5 & 0.22 & 2.0 & 0.13 & 0.00 & 10 & \mathbf{0 . 0 0 8}\end{array}$

\section{Physical Variables:}

snout-vent length $(\mathrm{mm})$

body-minus-head mass ( $\mathrm{g}$ )

$\begin{array}{ll}6.0 & 0.07\end{array}$

$\begin{array}{ll}6.0 & 0.10\end{array}$

0.00

$8 \quad 1.00$

testes mass $(\mathrm{g})$

$3.3 \quad 0.07$

3.4

0.08

$-0.75$

80.48

testosterone $(\mathrm{ng} / \mathrm{ml})$

$0.1 \quad 0.00$

0.1

0.01

$-0.26$

$\begin{array}{ll}8 & 0.80\end{array}$

estradiol $(\mathrm{ng} / \mathrm{ml})$

$2.2 \quad 1.08$

1.5

0.14

0.30

$\begin{array}{ll}8 & 0.77\end{array}$

progesterone $(\mathrm{ng} / \mathrm{ml})$

$9.3 \quad 5.68$

5.2

1.78

0.68

$\begin{array}{ll}8 & 0.74\end{array}$

glucocorticoids $(\mathrm{ng} / \mathrm{ml})$

$0.6 \quad 0.06$

$0.8 \quad 0.21$

$-0.97$

$\begin{array}{lll}4.8 & 0.59 & 0.25\end{array}$

$\begin{array}{ll}8 & 0.14\end{array}$

$7.0 \quad 3.14$

$\begin{array}{ll}8 & 0.81\end{array}$

Boldness is associated with gene upregulation in the ventromedial hypothalamus

We measured baseline gene expression in bold and shy individuals across six brain

regions that contribute to social decision-making and are functionally conserved across

vertebrates (Kabelik et al., 2018; Newman, 1999; O'Connell and Hofmann, 2012, 2011;

Thompson et al., 2008; Walton et al., 2010) (Figure 2A; Supplemental Excel File). We used a

principal component analysis to visualize overall gene expression differences across brain

regions and groups. Principal component (PC) 1 explained $22.8 \%$ of the variance, PC2 16.3\%,

and PC3 8.8\% (Figure 2B). Brain regions separated significantly in PC2 $\left(\mathrm{F}_{6,45}=463.4, \mathrm{p}<2 \times 10^{-}\right.$

$\left.{ }^{16}\right)$, but not by group or their interaction. Bold and shy groups separated significantly in PC3

$297\left(F_{1,45}=4.727, p=0.0372\right)$, but not by brain region or their interaction. The number of differentially 
301 individuals compared to shy individuals (Figure 2C), with the exception of the dorsal ventricular

302 ridge where expression of this gene was not detected. We also specifically examined genes that

303 are associated with bold or shy phenotypes in other taxa (Figure 2D), and every gene had

304 significant expression differences across brain regions (See Supplementary Excel File for

305 statistics). Only two genes had significant group by brain region interactions, where estrogen

306 receptor alpha (er $\alpha)$ was elevated in the ventromedial hypothalamus of bold lizards $(p=0.039)$

307 and corticotropin-releasing hormone $(c r h)$ was elevated in the hindbrain of shy males $(p=0.028)$.

Since the ventromedial hypothalamus had a drastically different pattern in baseline gene expression between bold and shy individuals, we explored these patterns in more detail (plots for all other brain regions are shown in Supplementary Figure 2). There were 601 genes upregulated and 7 downregulated in bold individuals compared to shy individuals (Figure 3A).

312 While many differentially expressed genes are unannotated and labeled as "novel transcripts",

313 we noted several that have established roles in regulating behavior or have a log fold change of

314 greater than 5 (Figure 3B). This includes the androgen receptor (ar, $\mathrm{p}=0.014)$ and the two

315 subunits of the NMDA receptor, grin1a $(p<0.001)$ and grin2b $(p<0.001)$. Expression of integrin

316 alpha-10 was downregulated in bold individuals $(p=0.017)$, similar to other brain regions. Finally,

317 some genes had a large fold change increase in bold individuals, including a potassium channel

318 (kcnh1-like, $\mathrm{p}>0.001)$ and the secretin receptor (sctr, $\mathrm{p}=0.02)$, To further explore gene

319 expression differences in an untargeted manner, we examined gene otology annotations for

320 differentially expressed genes and found enriched molecular function of calcium channel activity

$321\left(p=5.04 \times 10^{-4}\right)$. Indeed, at least seven voltage-gated calcium channel genes were upregulated in

322 bold individuals (Figure $3 \mathbf{C}$ ). 
Most behaviorally linked gene expression studies examine changes resulting from participation in behavioral trials or the establishment of dominant or subordinate status within a

327 social hierarchy. However, such comparisons make it difficult to ascertain what variables are

328 predisposing animals to exhibit a bold or shy phenotype in the first place, as such studies will

329 also detect gene transcription differences that result from the perception of conspecifics and

330 performance of varied levels of behaviors toward other individuals. Hence, to remove

331 perception-related and performance-based gene expression and focus on neural differences

332 that predispose individuals toward bold or shy behavioral profiles, we examined male green

333 anoles under baseline conditions. These anoles had been previously screened under three

334 different social conditions and repeatedly within each condition. We found highly stable

335 boldness phenotypes that transcended social context. That is, in relation to shy males, bold

336 males tended to behave more quickly and to exhibit greater numbers and higher intensities of

337 courtship behaviors within reproductive trials and of aggressive behaviors within agonistic trials.

338 This correlation of social boldness across contexts is in line with expectations for consistent

339 behavioral phenotypes or syndromes (Coppens et al., 2010; Koolhaas et al., 2010; Stamps and

340 Groothuis, 2010). Thus, our gene expression analysis investigates neural correlates of general

341 social boldness.

Because sequencing six brain regions from all 57 males in this study for the purposes of

343 covariation analysis was beyond our means, we instead chose to focus on a comparison of

344 individuals from the extreme ends of the normal boldness distribution found in this species. We

345 reasoned that such a comparison would maximize our chances of detecting gene expression

346 involved with the determination of social boldness. This approach has been used by other

347 researchers (e.g., Thörnqvist et al., 2019) and is akin to the breeding of more bold or shy lines

348 of rodents (Koolhaas et al., 2010) or zebrafish (Oswald et al., 2012; Wong et al., 2012a),

349 although our study examines wild-caught animals whose phenotypic variance has been 
maintained solely though natural selection processes, rather than artificial selection. Future studies will examine specific genes of interest in specific brain tissues across larger sample sizes varying continuously in measures of social boldness, allowing for examination of covariance across a normal distribution.

\section{Evolutionary bases for stable boldness phenotypes}

Behavioral boldness and stress coping styles appear to have strong heritable components (Ballew et al., 2017; Mont et al., 2018; Scherer et al., 2017) and variability of these traits within a population appears to be maintained by selective pressures (Koolhaas et al., 2010; Smith and Blumstein, 2010). Furthermore, as in this study, behavioral boldness in various species is stable, including across social contexts (hence eliciting the term behavioral syndrome) (Colléter and Brown, 2011; Koolhaas et al., 2010; Qu et al., 2018; Reaney and Backwell, 2007). This stability is likely due to underlying genetic correlations regulating behaviors across contexts (Oswald et al., 2013). In anole lizards, a finding of behavioral boldness stability across time was also recently reported in water anoles, Anolis aquaticus (Putman et al., 2019), supporting our results and a notion that behavioral boldness is a stable trait across anole species.

Studies of behavioral boldness have also shown that behavioral boldness is sometimes positively correlated with overall behavioral activity levels (Colléter and Brown, 2011; Smith and Blumstein, 2010; Wong et al., 2015). This association suggests the presence of shared behavioral circuitry beyond that for solely social behaviors. However, other studies find dissociations between locomotion and measures of boldness and stress responsiveness (Kanitz et al., 2019; Van Reenen et al., 2004), so such a correlation is not universal. General activity was not quantified in the present study, so future studies will need to determine whether bold 
374

375

376

377

378

379

380

381

382

383

male green anoles also exhibit greater general activity levels. Such a finding could provide evidence for increased behavioral display contributing to the increased frequency and decreased latency of displays during social interaction trials. However, a generally higher activity level in bold animals would less easily account for our finding of increased behavioral intensity in bold individuals, as activity levels in and of themselves would not determine whether an individual would, for instance, rather bite than flee from a conspecific during an agonistic trial.

Thus, we suspect that although general behavioral activity may correlate with behavioral boldness in green anoles, social behavior regulation seems to be regulated, at least in part, by separate mechanisms.

\section{Social boldness phenotype is unrelated to body size and circulating steroid hormone levels}

Some previous studies have found associations between behavioral boldness and measures of physical condition. These studies have focused on the enhanced physical abilities of bold individuals allowing them to better escape predators or obtain resources, thus providing fitness benefits (Mayer et al., 2016; Smith and Blumstein, 2010). A similar argument can be made that individuals in better physical condition may also be better combatants in agonistic encounters and thus bolder in such situations. However, while there were many behavioral differences between bold and shy individuals in this study, we did not find any group differences in body size. Furthermore, although body size has been found to correlate with boldness in a number of species (Adriaenssens and Johnsson, 2011; Brown and Braithwaite, 2004; Mayer et al., 2016), the direction of this correlation is not always consistent due to the underlying basis for the relationship. For example, smaller individuals of some species may need to leave shelter earlier to forage, while in other species a larger body size can allow individuals to avoid predation and more easily consume prey and thus allow larger individuals to more readily leave shelter. Additionally, other studies find no correlation between boldness and body size (Reaney 
and Backwell, 2007), presumably because no third variable drives such a relationship. The lack of relationship between body size and boldness in our study therefore suggests that boldness in male green anoles has fitness consequences largely independent of body size.

We initially hypothesized that there would be group differences in glucocorticoid hormone levels because a sub-section of studies that address behavioral boldness focus primarily on active versus passive coping styles to stressors, and some of these studies have found glucocorticoid differences between coping styles (Koolhaas et al., 2010; Sluyter et al.,

411 glucocorticoid levels and measures of boldness, while others do not (Koolhaas et al., 2010).

412 However, we must also consider additional variables such as time and context of hormone

413 sampling. Our hormone measures were from diurnal plasma samples, and thus we cannot

414 exclude the possibility of group differences in basal glucocorticoid release at other points in the 415 circadian cycle, such as those seen in zebrafish (Tudorache et al., 2018) and mice (Veenema et 416 al., 2004, 2003). Our hormone measures were also from baseline plasma samples, and thus we 417 cannot exclude the possibility of group differences in stress-induced glucocorticoid release. This 418 latter scenario may be possible given that we detected elevated crh in the hindbrain of shy 419 males, although we found no such difference in hypothalamic regions. Much variation exists in 420 the literature, with various findings across species, and even within single species, suggesting

421 that in some cases relationships exists between basal and/or stress-reactive glucocorticoid 422 levels and behavioral boldness, while in other cases such relationships are absent (Koolhaas et 423 al., 2010; Steimer et al., 1997). The concept of an (at least partial) dissociation between 
424 behavioral boldness and stress responsiveness in some species is supported by studies in rats,

425 cattle, and pika (Qu et al., 2018; Steimer et al., 1997; Van Reenen et al., 2005, 2004).

426 Research on stress-reactivity in green anoles is necessary to clarify whether such a dissociation

427 is present in this species.

Organizational effects of steroid hormones on social behavior phenotype are present in some species (Koolhaas et al., 2010) and may also be present in green anoles. However, we find no evidence for activational effects of steroid hormones on determining boldness phenotype in anoles, despite their presumed involvements in other aspects of behavioral motivation and display. We had expected that testosterone, estradiol, or progesterone levels could correlate with group differences in behavioral boldness because of the known involvement of these

434 hormones in the regulation of lizard social behaviors. In male tree lizards, circulating 435 testosterone correlates with aggression (Kabelik et al., 2006) and testosterone and 436 progesterone treatments causally promote aggression (Kabelik et al., 2008b; Weiss and Moore, 437 2004). Similarly, in male side-blotched lizards, circulating testosterone levels are higher in the 438 more aggressive morph (Sinervo et al., 2000), and the anti-androgen cyproterone acetate has 439 been found to reduce display behaviors in male brown anoles, toward both conspecific males 440 and females (Tokarz, 1995). Studies examining other vertebrate taxa and focusing on 441 behavioral boldness have found mixed associations with circulating steroid hormone levels. For 442 example, testosterone treatment in African striped mice (Rhabdomys pumilio) increases 443 boldness behavior (Raynaud and Schradin, 2014), and acute 17a-ethinylestradiol (an estrogen 444 mimic) decreases boldness behavior in Siamese fighting fish (Betta splendens). However, 445 aromatase inhibitors decrease boldness in female Siamese fighting fish, highlighting a role for 446 local hormone synthesis within the brain. When performing our targeted gene expression 447 analyses, we found that estrogen receptor alpha expression is increased in the ventromedial 
449 in this context. Functional manipulations would be required to determine a causal role for steroid

450 hormone action or synthesis in the brain and any relationships with individual variation in

451 behavior. Another example of how steroid hormones may influence boldness is via androgen

452 receptor expression. We further address this hypothesis below, in relation androgen receptor 453 differences between groups.

When comparing forebrain, midbrain, and hindbrain regions of bold versus shy male green anole lizards, we found the greatest number of differentially expressed genes within the ventromedial hypothalamus, a node within the social decision-making neural network (O'Connell and Hofmann, 2011). We were initially surprised to find so few genes differentially expressed within other brain regions, especially in regions such as the preoptic area, given its established

461 role in regulating male anole sexual behavior (Crews and Morgentaler, 1979; Kabelik et al.,

462 2013; Morgantaler and Crews, 1978; O’Bryant and Wade, 2002; Wheeler and Crews, 1978).

463 However, the patterns here represent a constitutive state, rather than a response to a

464 behavioral stimulus that would be expected to induce a greater change in gene expression across brain regions. The ventromedial hypothalamus has been implicated in the regulation of both reproductive and agonistic behaviors, making it a logical location for regulation of general

467 social behavior boldness. For instance, both copulatory and agonistic conditions have been

468 shown to upregulate markers of neural activity within the Syrian hamster ventromedial

469 hypothalamus, although copulation tends to induce more c-Fos expression (an immediate early 470 gene product and proxy marker of neural activity) in the medial portions of the nucleus, while 471 agonistic situations tend to increase c-Fos in the lateral ventromedial hypothalamus (Kollack-

472 Walker and Newman, 1995). Additionally, stimulation of the lateral portions of the rat

473 ventromedial hypothalamus has been shown to elicit aggressive responses (Kruk, 1991). The 
474

475

476

477

478

479

480

481

482

483

484

485

486

487

488

ventromedial hypothalamus therefore seems a likely social behavior integration center, owing to its regulatory role in various types of social behavior expression.

In the ventromedial hypothalamus, we observed increased gene expression of a few neuromodulators with strong ties to behavior. For example, although we did not find significant differences in testosterone levels between bold and shy individuals, we did find an increase in androgen receptor expression in bold individuals. This finding is exciting given that androgen receptor presence within the ventromedial hypothalamus occurs within its dorsolateral aspect (Rosen et al., 2002), the same region of the ventromedial hypothalamus that has been previously linked to the expression of aggressive behavior in male tree lizards (Kabelik et al., 2008a). Although they did not examine the ventromedial hypothalamus, Hattori and Wilczynski (2014) found increased androgen receptor expression in the preoptic area and anterior hypothalamus of green anoles that won agonistic encounters and became dominant to a samesex conspecific, further suggesting a role of the androgen receptor in mediating social interactions. Further studies will be necessary to determine whether social interactions likewise mediate androgen receptor expression within ventromedial hypothalamus.

We also found an increase in expression of the secretin receptor in bold individuals. Secretin is primarily known for its role in regulating neurodevelopment and memory function via effects on synaptic plasticity (Wang and Zhang, 2020). Synaptic plasticity, learning, and memory formation have been linked to stress coping styles and behavioral boldness (Bolhuis et al., 2004; Coppens et al., 2010; Delclos et al., 2020; Wong et al., 2015). Furthermore, secretin has also been shown to regulate anxiety and associated behaviors (Nishijima et al., 2006; Wang et al., 2019), as well as to modulate activity of reproductive circuitry (Csillag et al., 2019). More specifically, secretin regulates GABAergic transmission to gonadotropin-releasing hormoneproducing cells (Csillag et al., 2019), as well as affecting the firing rate of over $50 \%$ of examined paraventricular hypothalamus neurons in rat in vivo studies (Chen et al., 2013). These studies 
suggest a role for secretin as a widespread modulator of neural function, and as such, secretin

500

501

502

503

504

505

506

507

508

509

510

511

512

513

514

515

516

517

518 519 individual variation in behavior.

520

521

522

523 hypothalamus.

may also regulate social behavior via modulation of neuronal activity within the ventromedial

A prominent category of differentially expressed genes within the ventromedial hypothalamus, as revealed by the gene otology analysis, was voltage-gated calcium channels. Voltage-gated calcium channels regulate both intracellular calcium levels as well as general neuronal excitability, and have been linked to a number of neuropsychiatric symptoms in humans, including bipolar disorder, depression, and attention deficit hyperactivity disorder (Kabir et al., 2017). In addition to voltage-gated calcium channels, we also found that expression of ligand-gated calcium channel NMDA subunits is upregulated in bold individuals. NMDA receptor regulation has been linked to behavioral boldness in birds (Audet et al., 2018), suggesting the tuning of calcium channel expression may be a conserved feature of behavioral variability. Indeed, increased intracellular calcium levels induce signaling cascades that can lead to changes in transcription, such as the phosphorylation of cyclic adenosine monophosphate response element binding protein (CREB), which has been linked to synaptic, neuronal, and behavioral plasticity (Hofmann, 2003). In tree lizards, the dorsolateral portions of the ventromedial hypothalamus show increased neural activity as measured by an increase in pCREB following an agonistic encounter (Kabelik et al., 2008a). Thus, a number of neural activity-regulating channels differ in baseline gene expression between bold and shy males, highlighting neuronal excitability in the ventromedial hypothalamus as a contributor to stable

Across most brain regions, integrin alpha-10 was the one gene consistently downregulated in bold individuals. Integrins are typically associated with neuronal development, as they can detect and transmit mechanical force on extracellular matrices into an intracellular signal (Takada et al., 2007). The role of integrin alpha-10 is not well understood, especially in 
524 the context of behavior. Integrin alpha-10 in humans is associated with the 1q21.1 chromosomal

525 region, which when deleted leads to thrombocytopenia absent radius (TAR) (Brunetti-Pierri et

526 al., 2008). Genome wide association studies in humans has also linked integrin alpha-10 to

527 bipolar disorder (Pedroso et al., 2012). Thus, a role for integrin alpha-10 in natural variation in

528 behavioral strategies beyond that of human disease is a promising avenue of future research.

Other neuromodulators previous linked to coping styles in fish and mammals were not differentially expressed between bold and shy male green anoles, including dopamine, nonapeptides, and the glucocorticoids. We did find increased corticotropin releasing hormone expression in the hindbrain of bold males, but this should be interpreted with caution due to our low sample size. Bold zebrafish tend to have increased D2 receptor expression (Thörnqvist et al., 2019) and shy sea bass have increased glucocorticoid-related gene expression (Alfonso et al., 2019), but these studies analyzed whole brain gene expression patterns rather than specific brain regions. It is possible that D2 receptor or glucocorticoid-related gene expression may also differ between bold and shy male green anoles within brain regions not examined in our study. Studies on artificially selected lines of bold and shy zebrafish have found that shy lines have 539 elevated expression of glucocorticoid-related genes in pooled hypothalamus/midbrain/optic 540 tectum samples (Oswald et al., 2012) and neurometabolism genes in whole brain tissue (Wong 541 et al., 2015). We did not find strong evidence of group differences in expression of these genes, 542 which could be due to species differences in neural mechanisms or differences in design as the 543 fish study used artificially selected lines. Glucocorticoid receptors as well as nonapeptide 544 receptors have also been associated with coping styles in mammals, where Kanitz et al. (2019)

545 found differential brain gene expression in piglets exposed or not exposed to a stressor,

546 although only glucocorticoid receptor expression differences in the hypothalamus were apparent 547 between groups. In this same piglet study, V1a receptor differences were only present as 548 interaction effects with stress treatment and this was only observed within the hypothalamus. 
549 The lack of differential expression of these genes in hippocampal and amygdalar tissues is

550 consistent with our findings, while the findings in the hypothalamus are more difficult to interpret

551 since the entire hypothalamus was sampled in the pig study. Overall, the general patterns of

552 gene expression across taxa are difficult to compare given differences in behavioral paradigms

553 and tissue sampling. More consistent behavioral paradigms and brain region sampling across

554 taxa are needed for more fair comparisons.

\section{Conclusion}

Our study focuses on constitutive differences across bold or shy individuals by isolating

558 baseline hormone levels and brain gene expression profiles that influence social boldness

559 predisposition, rather than those reflecting the results of social interaction and behavioral

560 execution. We found that correlated behavioral traits were not driven by differences in body size

561 or steroid hormone levels, as these were consistent across treatment groups. Instead, brain

562 gene expression differences strongly relate to social boldness and likely reflect variables

563 involved in the neural circuitry that regulates social boldness. Specifically, we found that

564 baseline differences between bold and shy males were associated with gene expression in the

565 ventromedial hypothalamus, where expression of calcium channels, the androgen receptor, and

566 the secretin receptor were increased in bold individuals. We suggest that studies should include

567 examination of the ventromedial hypothalamus as a potential regulator of social behavior

568 boldness in reptiles as well as across other vertebrate taxa.

\section{Acknowledgements}


$574 \quad$ Funding

575

576

577

578

579

580

581

582

583

584

585

586

587

We gratefully acknowledge support from Rhodes College and the James T. and Valeria

B. Robertson Chair in Biological Sciences to DK and the National Institutes of Health

[DP2HD102042] to LAO. LAO is New York Stem Cell Foundation - Robertson Investigator.

\section{Declaration of competing interest}

The authors have no competing interest to declare.

\section{Data Accessibility}

Data from the behavior and hormone analyses, as well as RNA sequencing analysis, including count matrices, GO enrichment analyses, and differential expression statistics, are available in the Supplementary Excel File. Raw sequencing reads are available on the Sequence Read Archive (submission pending acceptance).

\section{References}

Adriaenssens, B., Johnsson, J.I., 2011. Shy trout grow faster: exploring links between personality and fitness-related traits in the wild. Behav. Ecol. 22, 135-143. https://doi.org/10.1093/beheco/arq185

Alföldi, J., Di Palma, F., Grabherr, M., Williams, C., Kong, L., Mauceli, E., Russell, P., Lowe, C.B., Glor, R.E., Jaffe, J.D., Ray, D.A., Boissinot, S., Shedlock, A.M., Botka, C., Castoe, T.A., Colbourne, J.K., Fujita, M.K., Moreno, R.G., ten Hallers, B.F., Haussler, D., Heger, A., Heiman, D., Janes, D.E., Johnson, J., de Jong, P.J., Koriabine, M.Y., Lara, M., Novick, P.A., Organ, C.L., Peach, S.E., Poe, S., Pollock, D.D., de Queiroz, K., Sanger, T., Searle, S., Smith, J.D., Smith, Z., Swofford, R., Turner-Maier, J., Wade, J., Young, S., Zadissa, A., Edwards, S. V, Glenn, T.C., Schneider, C.J., Losos, J.B., Lander, E.S., Breen, M., Ponting, C.P., Lindblad-Toh, K., 2011. The genome of the green anole lizard and a comparative 
600

601

602

603

604

605

606

607

608

609

610

611

612

613

614

615

616

617

618

619

620

621

622

623

624

625

626

627

628

629

630

631

632

633

634

635

636

637

638

639

640

641

642

analysis with birds and mammals. Nature 477, 587-591.

https://doi.org/10.1038/nature10390

Alfonso, S., Sadoul, B., Gesto, M., Joassard, L., Chatain, B., Geffroy, B., Bégout, M.-L., 2019. Coping styles in European sea bass: The link between boldness, stress response and neurogenesis. Physiol. Behav. 207, 76-85.

https://doi.org/https://doi.org/10.1016/j.physbeh.2019.04.020

Audet, J.-N., Kayello, L., Ducatez, S., Perillo, S., Cauchard, L., Howard, J.T., O'Connell, L.A., Jarvis, E.D., Lefebvre, L., 2018. Divergence in problem-solving skills is associated with differential expression of glutamate receptors in wild finches. Sci. Adv. 4, eaao6369. https://doi.org/10.1126/sciadv.aa06369

Ballew, N.G., Mittelbach, G.G., Scribner, K.T., 2017. Fitness consequences of boldness in juvenile and adult largemouth bass. Am. Nat. 189, 396-406. https://doi.org/10.1086/690909

Baugh, A.T., Schaper, S. V, Hau, M., Cockrem, J.F., de Goede, P., Oers, K. van, 2012. Corticosterone responses differ between lines of great tits (Parus major) selected for divergent personalities. Gen. Comp. Endocrinol. 175, 488-494. https://doi.org/https://doi.org/10.1016/j.ygcen.2011.12.012

Bolhuis, J.E., Schouten, W.G.P., Leeuw, J.A.D., Schrama, J.W., Wiegant, V.M., 2004. Individual coping characteristics, rearing conditions and behavioural flexibility in pigs. Behav. Brain Res. 152, 351-360. https://doi.org/10.1016/j.bbr.2003.10.024

Bray, N.L., Pimentel, H., Melsted, P., Pachter, L., 2016. Near-optimal probabilistic RNA-seq quantification. Nat. Biotechnol. 34, 525-527. https://doi.org/10.1038/nbt.3519

Briscoe, S.D., Albertin, C.B., Rowell, J.J., Ragsdale, C.W., 2018. Neocortical association cell types in the forebrain of birds and alligators. Curr. Biol. 28, 686-696.e6. https://doi.org/10.1016/j.cub.2018.01.036

Briscoe, S.D., Ragsdale, C.W., 2018. Homology, neocortex, and the evolution of developmental mechanisms. Science (80-. ). 362, 190 LP - 193. https://doi.org/10.1126/science.aau3711

Brown, C., Braithwaite, V.A., 2004. Size matters: a test of boldness in eight populations of the poeciliid Brachyraphis episcopi. Anim. Behav. 68, 1325-1329. https://doi.org/https://doi.org/10.1016/j.anbehav.2004.04.004

Bruce, L.L., Braford, M.R., 2009. Evolution of the limbic system, in: Squire, L.R.B.T.-E. of N. (Ed.), Encyclopedia of Neuroscience. Academic Press, Oxford, pp. 43-55. https://doi.org/10.1016/B978-008045046-9.00965-7

Brunetti-Pierri, N., Berg, J.S., Scaglia, F., Belmont, J., Bacino, C.A., Sahoo, T., Lalani, S.R., Graham, B., Lee, B., Shinawi, M., Shen, J., Kang, S.-H.L., Pursley, A., Lotze, T., Kennedy, G., Lansky-Shafer, S., Weaver, C., Roeder, E.R., Grebe, T.A., Arnold, G.L., Hutchison, T., Reimschisel, T., Amato, S., Geragthy, M.T., Innis, J.W., Obersztyn, E., Nowakowska, B., Rosengren, S.S., Bader, P.I., Grange, D.K., Naqvi, S., Garnica, A.D., Bernes, S.M., Fong, C.-T., Summers, A., Walters, W.D., Lupski, J.R., Stankiewicz, P., Cheung, S.W., Patel, A., 2008. Recurrent reciprocal 1q21.1 deletions and duplications associated with microcephaly or macrocephaly and developmental and behavioral abnormalities. Nat. Genet. 40, 14661471. https://doi.org/10.1038/ng.279

Butler, A.B., Hodos, W., 2005. Comparative vertebrate neuroanatomy: Evolution and 
666

667

668

669

670

671

672

673

674

675

676

677

678

679

680

681

682

683

684

adaptation, 2nd ed, Comparative Vertebrate Neuroanatomy: Evolution and Adaptation:

Second Edition. John Wiley \& Sons. https://doi.org/10.1002/0471733849

Chen, X.-Y., Wang, H., Xue, Y., Chen, L., 2013. Modulation of paraventricular firing rate by secretin in vivo. Neurosci. Lett. 532, 29-32. https://doi.org/https://doi.org/10.1016/j.neulet.2012.10.055

Colléter, M., Brown, C., 2011. Personality traits predict hierarchy rank in male rainbowfish social groups. Anim. Behav. 81, 1231-1237. https://doi.org/https://doi.org/10.1016/j.anbehav.2011.03.011

Colquitt, B.M., Merullo, D.P., Konopka, G., Roberts, T.F., Brainard, M.S., 2021. Cellular transcriptomics reveals evolutionary identities of songbird vocal circuits. Science (80-. ). 371, eabd9704. https://doi.org/10.1126/science.abd9704

Coppens, C.M., De Boer, S.F., Koolhaas, J.M., 2010. Coping styles and behavioural flexibility: Towards underlying mechanisms. Philos. Trans. R. Soc. B Biol. Sci. 365, 4021-4028. https://doi.org/10.1098/rstb.2010.0217

Crews, D., Morgentaler, A., 1979. Effects of intracranial implantation of oestradiol and dihydrotestosterone on the sexual behavior of the lizard Anolis carolinensis. J. Endocrinol. 82, 373-381. https://doi.org/10.1677/joe.0.0820373

Csillag, V., Vastagh, C., Liposits, Z., Farkas, I., 2019. Secretin regulates excitatory GABAergic neurotransmission to $\mathrm{GnRH}$ neurons via retrograde NO signaling pathway in mice. Front. Cell. Neurosci. 13, 371. https://doi.org/10.3389/fncel.2019.00371

Delclos, P.J., Forero, S.A., Rosenthal, G.G., 2020. Divergent neurogenomic responses shape social learning of both personality and mate preference. J. Exp. Biol. 223, jeb220707. https://doi.org/10.1242/jeb.220707

Desfilis, E., Abellán, A., Sentandreu, V., Medina, L., 2018. Expression of regulatory genes in the embryonic brain of a lizard and implications for understanding pallial organization and evolution. J. Comp. Neurol. 526, 166-202. https://doi.org/10.1002/cne.24329

Dunham, L.A., Wilczynski, W., 2014. Arginine vasotocin, steroid hormones and social behavior in the green anole lizard (Anolis carolinensis). J. Exp. Biol. 217, 3670-3676. https://doi.org/10.1242/jeb.107854

Eastman, G., Valiño, G., Radío, S., Young, R.L., Quintana, L., Zakon, H.H., Hofmann, H.A., Sotelo-Silveira, J., Silva, A., 2020. Brain transcriptomics of agonistic behaviour in the weakly electric fish Gymnotus omarorum, a wild teleost model of non-breeding aggression. Sci. Rep. 10, 9496. https://doi.org/10.1038/s41598-020-66494-9

Félix, A.S., Cardoso, S.D., Roleira, A., Oliveira, R.F., 2020. Forebrain transcriptional response to transient changes in circulating androgens in a cichlid fish. G3 Genes, Genomes, Genet. 10, 1971-1982. https://doi.org/10.1534/g3.119.400947

Geng, Y., Peterson, R.T., 2019. The zebrafish subcortical social brain as a model for studying social behavior disorders. DMM Dis. Model. Mech. 12. https://doi.org/10.1242/dmm.039446

Gesto, M., 2019. Consistent individual competitive ability in rainbow trout as a proxy for coping style and its lack of correlation with cortisol responsiveness upon acute stress. Physiol. Behav. 208, 112576. https://doi.org/10.1016/j.physbeh.2019.112576

Greenberg, N., 1982. A forebrain atlas and stereotaxic technique for the lizard, Anolis 

carolinensis . J. Morphol. 174, 217-236. https://doi.org/10.1002/jmor.1051740210

Greenberg, N., Crews, D., 1990. Endocrine and behavioral responses to aggression and social dominance in the green anole lizard, Anolis carolinensis. Gen. Comp. Endocrinol. 77, 246255. https://doi.org/https://doi.org/10.1016/0016-6480(90)90309-A

Hartline, J.T., Smith, A.N., Kabelik, D., 2017. Serotonergic activation during courtship and aggression in the brown anole, Anolis sagrei. PeerJ 2017, e3331. https://doi.org/10.7717/peerj.3331

Hattori, T., Wilczynski, W., 2014. Differences in forebrain androgen receptor expression in winners and losers of male anole aggressive interactions. Brain Res. 1582, 45-54. https://doi.org/10.1016/j.brainres.2014.07.028

Hofmann, H.A., 2003. Functional genomics of neural and behavioral plasticity. J. Neurobiol. 54, 272-282. https://doi.org/https://doi.org/10.1002/neu.10172

Hoops, D., Desfilis, E., Ullmann, J.F.P., Janke, A.L., Stait-Gardner, T., Devenyi, G.A., Price, W.S., Medina, L., Whiting, M.J., Keogh, J.S., 2018. A 3D MRI-based atlas of a lizard brain. J. Comp. Neurol. https://doi.org/10.1002/cne.24480

Jarvis, E.D., 2008. Evolution of the Pallium in Birds and Reptiles, in: Binder, M.D., Hirokawa, N., Windhorst, U. (Eds.), Encyclopedia of Neuroscience. Springer Berlin Heidelberg, Berlin, Heidelberg, pp. 1390-1400. https://doi.org/10.1007/978-3-540-29678-2_3165

Kabelik, D., Alix, V.C., Burford, E.R., Singh, L.J., 2013. Aggression- and sex-induced neural activity across vasotocin populations in the brown anole. Horm. Behav. 63, 437-446. https://doi.org/10.1016/j.yhbeh.2012.11.016

Kabelik, D., Alix, V.C., Singh, L.J., Johnson, A.L., Choudhury, S.C., Elbaum, C.C., Scott, M.R., 2014. Neural activity in catecholaminergic populations following sexual and aggressive interactions in the brown anole, Anolis sagrei. Brain Res. 1553, 41-58. https://doi.org/10.1016/j.brainres.2014.01.026

Kabelik, D., Crews, D., 2017. Hormones, Brain, and Behavior in Reptiles, in: Hormones, Brain and Behavior: Third Edition. pp. 171-213. https://doi.org/10.1016/B978-0-12-8035924.00027-4

Kabelik, D., Crombie, T., Moore, M.C., 2008a. Aggression frequency and intensity, independent of testosterone levels, relate to neural activation within the dorsolateral subdivision of the ventromedial hypothalamus in the tree lizard Urosaurus ornatus. Horm. Behav. 54, 18-27. https://doi.org/10.1016/j.yhbeh.2007.09.022

Kabelik, D., Hofmann, H.A., 2018. Comparative neuroendocrinology: A call for more study of reptiles! Horm. Behav. 106, 189-192. https://doi.org/10.1016/j.yhbeh.2018.10.005

Kabelik, D., Magruder, D.S., 2014. Involvement of different mesotocin (oxytocin homologue) populations in sexual and aggressive behaviours of the brown anole. Biol. Lett. 10, 20140566. https://doi.org/10.1098/rsbl.2014.0566

Kabelik, D., Weiss, S.L., Moore, M.C., 2008b. Steroid hormones alter neuroanatomy and aggression independently in the tree lizard. Physiol. Behav. 93, 492-501. https://doi.org/10.1016/j.physbeh.2007.10.008

Kabelik, D., Weiss, S.L., Moore, M.C., 2006. Steroid hormone mediation of limbic brain plasticity and aggression in free-living tree lizards, Urosaurus ornatus. Horm. Behav. 49, 587-597. 
https://doi.org/10.1016/j.yhbeh.2005.12.004

767

768

Kabelik, D., Weitekamp, C.A., Choudhury, S.C., Hartline, J.T., Smith, A.N., Hofmann, H.A., 2018. Neural activity in the social decision-making network of the brown anole during reproductive and agonistic encounters. Horm. Behav. 106, 178-188. https://doi.org/10.1016/j.yhbeh.2018.06.013

Kabir, Z.D., Martínez-Rivera, A., Rajadhyaksha, A.M., 2017. From gene to behavior: L-type calcium channel mechanisms underlying neuropsychiatric symptoms. Neurotherapeutics 14, 588-613. https://doi.org/10.1007/s13311-017-0532-0

Kanitz, E., Tuchscherer, M., Otten, W., Tuchscherer, A., Zebunke, M., Puppe, B., 2019. Coping style of pigs is associated with different behavioral, neurobiological and immune responses to stressful challenges. Front. Behav. Neurosci. https://doi.org/10.3389/fnbeh.2019.00173

Ketterson, E.D., Nolan Val, J., 1999. Adaptation, exaptation, and constraint: A hormonal perspective. Am. Nat. 154, S4-S25. https://doi.org/10.1086/303280

Kollack-Walker, S., Newman, S.W., 1995. Mating and agonistic behavior produce different patterns of Fos immunolabeling in the male Syrian hamster brain. Neuroscience 66, 721736. https://doi.org/https://doi.org/10.1016/0306-4522(94)00563-K

Koolhaas, J.M., de Boer, S.F., Coppens, C.M., Buwalda, B., 2010. Neuroendocrinology of coping styles: Towards understanding the biology of individual variation. Front. Neuroendocrinol. 31, 307-321. https://doi.org/10.1016/j.yfrne.2010.04.001

Korzan, W.J., Summers, C.H., 2004. Serotonergic response to social stress and artificial social sign stimuli during paired interactions between male Anolis carolinensis. Neuroscience 123, 835-845. https://doi.org/https://doi.org/10.1016/j.neuroscience.2003.11.005

Korzan, W.J., Summers, T.R., Ronan, P.J., Renner, K.J., Summers, C.H., 2001. The role of monoaminergic nuclei during aggression and sympathetic social signaling. Brain. Behav. Evol. 57, 317-327. https://doi.org/10.1159/000047250

Kruk, M.R., 1991. Ethology and pharmacology of hypothalamic aggression in the rat. Neurosci. Biobehav. Rev. 15, 527-538. https://doi.org/https://doi.org/10.1016/S0149-7634(05)801447

Lanuza, E., 1998. Identification of the reptilian basolateral amygdala: An anatomical investigation of the afferents to the posterior dorsal ventricular ridge of the lizard Podarcis hispanica. Eur. J. Neurosci. 10, 3517-3534. https://doi.org/10.1046/j.14609568.1998.00363.x

Larson, E.T., Summers, C.H., 2001. Serotonin reverses dominant social status. Behav. Brain Res. 121, 95-102. https://doi.org/https://doi.org/10.1016/S0166-4328(00)00393-4

Lopez, K.H., Jones, R.E., Seufert, D.W., Rand, M.S., Dores, R.M., 1992. Catecholaminergic cells and fibers in the brain of the lizard Anolis carolinensis identified by traditional as well as whole-mount immunohistochemistry. Cell Tissue Res. 270, 319-337. https://doi.org/10.1007/BF00328017

Love, M.I., Huber, W., Anders, S., 2014. Moderated estimation of fold change and dispersion for RNA-seq data with DESeq2. Genome Biol. 15, 550. https://doi.org/10.1186/s13059-0140550-8

Lovern, M.B., Holmes, M.M., Wade, J., 2004. The green anole (Anolis carolinensis): A reptilian 
801

802

803

804

805 806

807

808

809

810

model for laboratory studies of reproductive morphology and behavior. ILAR J. https://doi.org/10.1093/ilar.45.1.54

Martínez-García, F., Martínez-Marcos, A., Lanuza, E., 2002. The pallial amygdala of amniote vertebrates: evolution of the concept, evolution of the structure, in: Brain Research Bulletin. pp. 463-469. https://doi.org/10.1016/S0361-9230(01)00665-7

Mayer, M., Shine, R., Brown, G.P., 2016. Bigger babies are bolder: effects of body size on personality of hatchling snakes. Behaviour 153, 313-323. https://doi.org/https://doi.org/10.1163/1568539X-00003343

Mi, H., Muruganujan, A., Ebert, D., Huang, X., Thomas, P.D., 2019. PANTHER version 14: more genomes, a new PANTHER GO-slim and improvements in enrichment analysis tools. Nucleic Acids Res. 47, D419-D426. https://doi.org/10.1093/nar/gky1038

Mont, C., Hernandez-Pliego, P., Cañete, T., Oliveras, I., Río-Álamos, C., Blázquez, G., LópezAumatell, R., Martínez-Membrives, E., Tobeña, A., Flint, J., Fernández-Teruel, A., Mott, R., 2018. Coping-style behavior identified by a survey of parent-of-origin effects in the rat. G3 Genes, Genomes, Genet. 8, 3283-3291. https://doi.org/10.1534/g3.118.200489

Morgantaler, A., Crews, D., 1978. Role of the anterior hypothalamus-preoptic area in the regulation of reproductive behavior in the lizard, Anolis carolinensis: Implantation studies. Horm. Behav. 11, 61-73. https://doi.org/10.1016/0018-506X(78)90058-2

Mukai, M., Replogle, K., Drnevich, J., Wang, G., Wacker, D., Band, M., Clayton, D.F., Wingfield, J.C., 2009. Seasonal differences of gene expression profiles in song sparrow (Melospiza melodia) hypothalamus in relation to territorial aggression. PLoS One 4, e8182. https://doi.org/10.1371/journal.pone.0008182

Naik, D.R., Sar, M., Stumpf, W.E., 1981. Immunohistochemical localization of enkephalin in the central nervous system and pituitary of the lizard, Anolis carolinensis. J. Comp. Neurol. 198, 583-601. https://doi.org/10.1002/cne.901980404

Newman, S.W., 1999. The medial extended amygdala in male reproductive behavior. A node in the mammalian social behavior network. Ann. N. Y. Acad. Sci. 877, 242-257. https://doi.org/10.1111/j.1749-6632.1999.tb09271.x

Nishijima, I., Yamagata, T., Spencer, C.M., Weeber, E.J., Alekseyenko, O., Sweatt, J.D., Momoi, M.Y., Ito, M., Armstrong, D.L., Nelson, D.L., Paylor, R., Bradley, A., 2006. Secretin receptor-deficient mice exhibit impaired synaptic plasticity and social behavior. Hum. Mol. Genet. 15, 3241-3250. https://doi.org/10.1093/hmg/ddl402

Northcutt, R.G., 1981. Evolution of the Telencephalon in Nonmammals. Annu. Rev. Neurosci. 4, 301-350. https://doi.org/10.1146/annurev.ne.04.030181.001505

O'Bryant, E.L., Wade, J., 2002. Seasonal and sexual dimorphisms in the green anole forebrain. Horm. Behav. 41, 384-395. https://doi.org/10.1006/hbeh.2002.1778

O'Connell, L.A., Hofmann, H.A., 2012. Evolution of a vertebrate social decision-making network. Science (80-. ). 336, 1154-1157. https://doi.org/10.1126/science.1218889

O'Connell, L.A., Hofmann, H.A., 2011. The vertebrate mesolimbic reward system and social behavior network: A comparative synthesis. J. Comp. Neurol. 519, 3599-3639. https://doi.org/10.1002/cne.22735

Oswald, M.E., Drew, R.E., Racine, M., Murdoch, G.K., Robison, B.D., 2012. Is behavioral 
841

842

843

844

845

846

variation along the bold-shy continuum associated with variation in the stress axis in zebrafish? Physiol. Biochem. Zool. 85, 717-728. https://doi.org/10.1086/668203

Oswald, M.E., Singer, M., Robison, B.D., 2013. The quantitative genetic architecture of the boldshy continuum in zebrafish, Danio rerio. PLoS One 8 , e68828. https://doi.org/10.1371/journal.pone.0068828

Pedroso, I., Lourdusamy, A., Rietschel, M., Nöthen, M.M., Cichon, S., McGuffin, P., Al-Chalabi, A., Barnes, M.R., Breen, G., 2012. Common genetic variants and gene-expression changes associated with bipolar disorder are over-represented in brain signaling pathway genes. Biol. Psychiatry 72, 311-317. https://doi.org/10.1016/j.biopsych.2011.12.031

Putman, B.J., Azure, K.R., Swierk, L., 2019. Dewlap size in male water anoles associates with consistent inter-individual variation in boldness. Curr. Zool. 65, 189-195. https://doi.org/10.1093/cz/zoy041

Qu, J., Fletcher, Q.E., Réale, D., Li, W., Zhang, Y., 2018. Independence between coping style and stress reactivity in plateau pika. Physiol. Behav. 197, 1-8. https://doi.org/https://doi.org/10.1016/j.physbeh.2018.09.007

Raynaud, J., Schradin, C., 2014. Experimental increase of testosterone increases boldness and decreases anxiety in male African striped mouse helpers. Physiol. Behav. 129, 57-63. https://doi.org/https://doi.org/10.1016/j.physbeh.2014.02.005

Réale, D., Dingemanse, N.J., Kazem, A.J.N., Wright, J., 2010. Evolutionary and ecological approaches to the study of personality. Philos. Trans. R. Soc. B Biol. Sci. 365, 3937-3946. https://doi.org/10.1098/rstb.2010.0222

Reaney, L.T., Backwell, P.R.Y., 2007. Risk-taking behavior predicts aggression and mating success in a fiddler crab. Behav. Ecol. 18, 521-525. https://doi.org/10.1093/beheco/arm014

Renn, S.C.P., Aubin-Horth, N., Hofmann, H.A., 2008. Fish and chips: functional genomics of social plasticity in an African cichlid fish. J. Exp. Biol. 211, 3041 LP - 3056. https://doi.org/10.1242/jeb.018242

Rosen, G., O’Bryant, E., Matthews, J., Zacharewski, T., Wade, J., 2002. Distribution of androgen receptor mRNA expression and immunoreactivity in the brain of the green anole lizard. J. Neuroendocrinol. 14, 19-28. https://doi.org/10.1046/j.0007-1331.2001.00735.x

Scherer, U., Kuhnhardt, M., Schuett, W., 2017. Different or alike? Female rainbow kribs choose males of similar consistency and dissimilar level of boldness. Anim. Behav. 128, 117-124. https://doi.org/https://doi.org/10.1016/j.anbehav.2017.04.007

Sih, A., Bell, A., Johnson, J.C., 2004. Behavioral syndromes: an ecological and evolutionary overview. Trends Ecol. Evol. 19, 372-378. https://doi.org/10.1016/j.tree.2004.04.009

Sinervo, B., Miles, D.B., Frankino, W.A., Klukowski, M., DeNardo, D.F., 2000. Testosterone, endurance, and Darwinian fitness: Natural and sexual selection on the physiological bases of alternative male behaviors in side-blotched lizards. Horm. Behav. 38, 222-233. https://doi.org/10.1006/hbeh.2000.1622

Sluyter, F., Korte, S.M., Bohus, B., Van Oortmerssen, G.A., 1996. Behavioral stress response of genetically selected aggressive and nonaggressive wild house mice in the shockprobe/defensive burying test. Pharmacol. Biochem. Behav. 54, 113-116. https://doi.org/10.1016/0091-3057(95)02164-7 
854

855

856

857

858

859

860

861

862

863

864

865

866

867

868

869

870

871

872

873

874

875

876

877

878

879

880

881

882

883

884

885

886

887

888

889

890

891

892

893

894

895

896

Smith, A.N., Kabelik, D., 2017. The effects of dopamine receptor 1 and 2 agonists and antagonists on sexual and aggressive behaviors in male green anoles. PLoS One 12. https://doi.org/10.1371/journal.pone.0172041

Smith, B.R., Blumstein, D.T., 2010. Behavioral types as predictors of survival in Trinidadian guppies (Poecilia reticulata). Behav. Ecol. 21, 919-926. https://doi.org/10.1093/beheco/arq084

Stamps, J., Groothuis, T.G.G., 2010. The development of animal personality: relevance, concepts and perspectives. Biol. Rev. 85, 301-325. https://doi.org/https://doi.org/10.1111/j.1469-185X.2009.00103.x

Steimer, T., La Fleur, S., Schulz, P.E., 1997. Neuroendocrine correlates of emotional reactivity and coping in male rats from the Roman high (RHA/Verh)-and low (RLA/Verh)-avoidance lines. Behav. Genet. 27, 503-512. https://doi.org/10.1023/A:1021448713665

Striedter, G.F., 2016. Evolution of the hippocampus in reptiles and birds. J. Comp. Neurol. 524, 496-517. https://doi.org/10.1002/cne.23803

Takada, Y., Ye, X., Simon, S., 2007. The integrins. Genome Biol. 8, 215. https://doi.org/10.1186/gb-2007-8-5-215

ten Donkelaar, H.J., 1998. Reptiles, in: The Central Nervous System of Vertebrates. Springer Berlin Heidelberg, Berlin, Heidelberg, pp. 1315-1524. https://doi.org/10.1007/978-3-64218262-4_20

Thompson, R.R., Walton, J.C., Bhalla, R., George, K.C., Beth, E.H., 2008. A primitive social circuit: Vasotocin-substance $P$ interactions modulate social behavior through a peripheral feedback mechanism in goldfish. Eur. J. Neurosci. 27, 2285-2293. https://doi.org/10.1111/j.1460-9568.2008.06210.x

Thörnqvist, P.-O., McCarrick, S., Ericsson, M., Roman, E., Winberg, S., 2019. Bold zebrafish (Danio rerio) express higher levels of delta opioid and dopamine D2 receptors in the brain compared to shy fish. Behav. Brain Res. 359, 927-934. https://doi.org/https://doi.org/10.1016/j.bbr.2018.06.017

Tokarz, R.R., 1995. Importance of androgens in male territorial acquisition in the lizard Anolis sagrei: an experimental test. Anim. Behav. 49, 661-669. https://doi.org/10.1016/00033472(95)80199-5

Tosches, M.A., Yamawaki, T.M., Naumann, R.K., Jacobi, A.A., Tushev, G., Laurent, G., 2018. Evolution of pallium, hippocampus, and cortical cell types revealed by single-cell transcriptomics in reptiles. Science (80-. ). 360, 881 LP - 888. https://doi.org/10.1126/science.aar4237

Tudorache, C., Slabbekoorn, H., Robbers, Y., Hin, E., Meijer, J.H., Spaink, H.P., Schaaf, M.J.M., 2018. Biological clock function is linked to proactive and reactive personality types. BMC Biol. 16, 148. https://doi.org/10.1186/s12915-018-0618-0

Van Reenen, C.G., Engel, B., Ruis-Heutinck, L.F.M., Van Der Werf, J.T.N., Buist, W.G., Jones, R.B., Blokhuis, H.J., 2004. Behavioural reactivity of heifer calves in potentially alarming test situations: A multivariate and correlational analysis. Appl. Anim. Behav. Sci. 85, 11-30. https://doi.org/10.1016/j.applanim.2003.09.007

Van Reenen, C.G., O’Connell, N.E., Van Der Werf, J.T.N., Korte, S.M., Hopster, H., Jones, R.B., Blokhuis, H.J., 2005. Responses of calves to acute stress: Individual consistency and 
relations between behavioral and physiological measures. Physiol. Behav. 85, 557-570. https://doi.org/10.1016/j.physbeh.2005.06.015

Veenema, A.H., Koolhaas, J.M., De Kloet, E.R., 2004. Basal and stress-induced differences in HPA axis, 5-HT responsiveness, and hippocampal cell proliferation in two mouse lines. Ann. N. Y. Acad. Sci. 1018, 255-265. https://doi.org/10.1196/annals.1296.030

Veenema, A.H., Meijer, O.C., De Kloet, E.R., Koolhaas, J.M., Bohus, B.G., 2003. Differences in basal and stress-induced HPA regulation of wild house mice selected for high and low aggression. Horm. Behav. 43, 197-204. https://doi.org/10.1016/S0018-506X(02)00013-2

Walton, J.C., Waxman, B., Hoffbuhr, K., Kennedy, M., Beth, E., Scangos, J., Thompson, R.R., 2010. Behavioral effects of hindbrain vasotocin in goldfish are seasonally variable but not sexually dimorphic. Neuropharmacology 58, 126-134. https://doi.org/10.1016/j.neuropharm.2009.07.018

Wang, L., Zhang, L., 2020. Involvement of secretin in the control of cell survival and synaptic plasticity in the central nervous system. Front. Neurosci. 14, 387. https://doi.org/10.3389/fnins.2020.00387

Wang, R., Chow, B.K.C., Zhang, L., 2019. Distribution and functional implication of secretin in multiple brain regions. J. Mol. Neurosci. 68, 485-493. https://doi.org/10.1007/s12031-018$1089-z$

Watt, M.J., Forster, G.L., Korzan, W.J., Renner, K.J., Summers, C.H., 2007. Rapid neuroendocrine responses evoked at the onset of social challenge. Physiol. Behav. 90, 567-575. https://doi.org/https://doi.org/10.1016/j.physbeh.2006.11.006

Weiss, S.L., Moore, M.C., 2004. Activation of aggressive behavior by progesterone and testosterone in male tree lizards, Urosaurus ornatus. Gen. Comp. Endocrinol. 136, 282288. https://doi.org/https://doi.org/10.1016/j.ygcen.2004.01.001

Wheeler, J.M., Crews, D., 1978. The role of the anterior hypothalamus-preoptic area in the regulation of male reproductive behavior in the lizard, Anolis carolinensis: Lesion studies. Horm. Behav. 11, 42-60. https://doi.org/10.1016/0018-506X(78)90057-0

Wong, R.Y., Lamm, M.S., Godwin, J., 2015. Characterizing the neurotranscriptomic states in alternative stress coping styles. BMC Genomics 16, 425. https://doi.org/10.1186/s12864015-1626-x

Wong, R.Y., Perrin, F., Oxendine, S.E., Kezios, Z.D., Sawyer, S., Zhou, L., Dereje, S., Godwin, J., 2012a. Comparing behavioral responses across multiple assays of stress and anxiety in zebrafish (Danio rerio). Behaviour 149, 1205-1240. https://doi.org/10.1163/1568539X00003018

Wong, R.Y., Ramsey, M.E., Cummings, M.E., 2012b. Localizing brain regions associated with female mate preference behavior in a swordtail. PLoS One 7, e50355. https://doi.org/10.1371/journal.pone.0050355

Woolley, S.C., Sakata, J.T., Crews, D., 2004a. Tyrosine hydroxylase expression is affected by sexual vigor and social environment in male Cnemidophorus inornatus. J. Comp. Neurol. 476, 429-439. https://doi.org/10.1002/cne.20236

Woolley, S.C., Sakata, J.T., Crews, D., 2004b. Evolutionary insights into the regulation of courtship behavior in male amphibians and reptiles. Physiol. Behav. 83, 347-360. https://doi.org/10.1016/j.physbeh.2004.08.021 
940

941

942

943

944

945

946

947

948

949

950

951

952

953

954

955

956

957

958

959

960

961

962

963

964

965

966

Woolley, S.C., Sakata, J.T., Gupta, A., Crews, D., 2001. Evolutionary changes in dopaminergic modulation of courtship behavior in Cnemidophorus whiptail lizards. Horm. Behav. 40, 483-489. https://doi.org/10.1006/hbeh.2001.1713

Zayed, A., Robinson, G.E., 2012. Understanding the relationship between brain gene expression and social behavior: Lessons from the honey bee. Annu. Rev. Genet. 46, 591615. https://doi.org/10.1146/annurev-genet-110711-155517

\section{Figure Captions}

Figure 1. Focal male green anole lizards exhibit stable social boldness phenotypes. (Left) Average boldness in three reproductive encounters correlates strongly with average boldness as the resident male in three separate agonistic encounters. (Middle) Average boldness as the resident male correlates strongly with average boldness as an intruder within three separate agonistic encounters. (Right) Average boldness as the intruder male in three separate agonistic encounters correlates weakly with average reproductive boldness to three pairs of females. Social boldness is represented by PCA axis 1 values, which are positively correlated with average behavioral frequency and intensity, and negatively correlated with average latency to display, within each behavioral encounter scenario. Trials were carried out in three blocks. One to two focal males with the highest combined PCA values per block ('bold', shown in bluegreen), and one to two focal males with the lowest combined PCA values per block ('shy', shown in orange) were selected for the bold-shy neural RNA sequencing comparison.

Figure 2. Baseline brain gene expression in bold and shy anoles. (A) RNA sequencing was used to quantify gene expression in six different brain regions in bold (orange) and shy (bluegreen) individuals. The number of differentially expressed genes in each brain region is shown in the Venn diagrams. (B) A principal component analysis shows separation between brain regions (different colors) in PC2 and behavioral group (bold in squares and shy in triangles) in PC3. Ellipses show 95\% confidence interval for each grouping. (C) Integrin alpha-10 (itga10) 
967 was downregulated in bold anoles across almost all brain regions. The log fold change (log2FC)

968 is shown in bar plots. (D) A heatmap shows normalized expression of genes previously

969 associated with bold and shy behaviors in other taxa (see text for references). Color bars below

970 the dendrogram shows brain region and behavior groupings. The color key for the heat map

971 shows green as increased expression and pink as decreased expression normalized within

972 each gene.

973

974 Figure 3. Baseline brain gene expression in bold and shy anoles highlights the

975 ventromedial hypothalamus. (A) A volcano plot highlights the genes that are differentially

976 expressed in the ventromedial hypothalamus, where the cutoff for significance (red dots beyond

977 the dashed lines) is $p<0.05$ with false discovery rate correction and a log fold change of two or

978 greater. (B) Genes previous linked to behavior and/or with large fold changes in expression and

979 (C) voltage-gated calcium channels from the gene ontology analysis are shown as boxplots,

980 with rectangles as the lower and upper quartiles (with the median as the line) and whiskers that

981 indicate the maximum and minimum values; individual data points are shown as dots. 


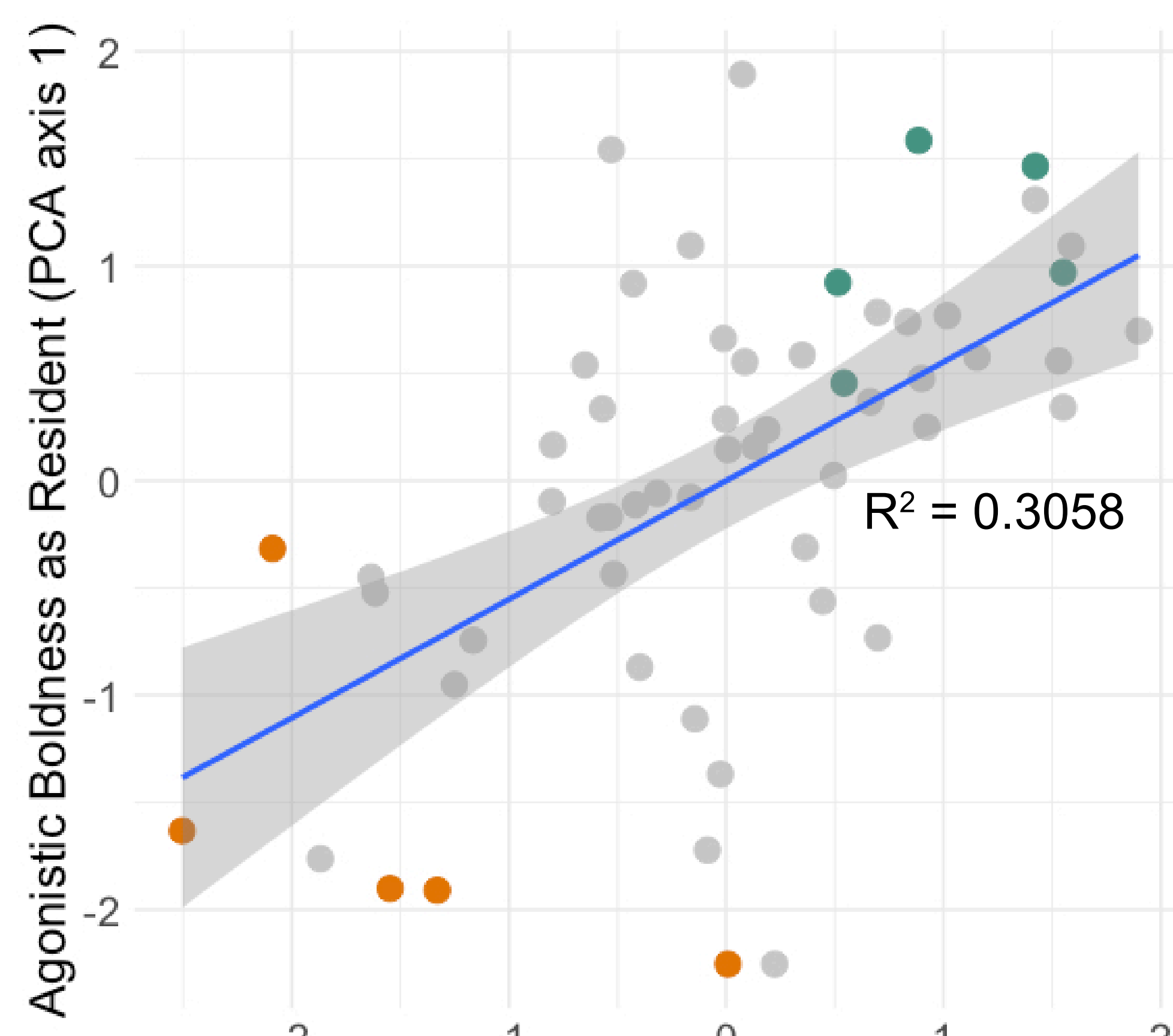

Reproductive Boldness (PCA axis 1)

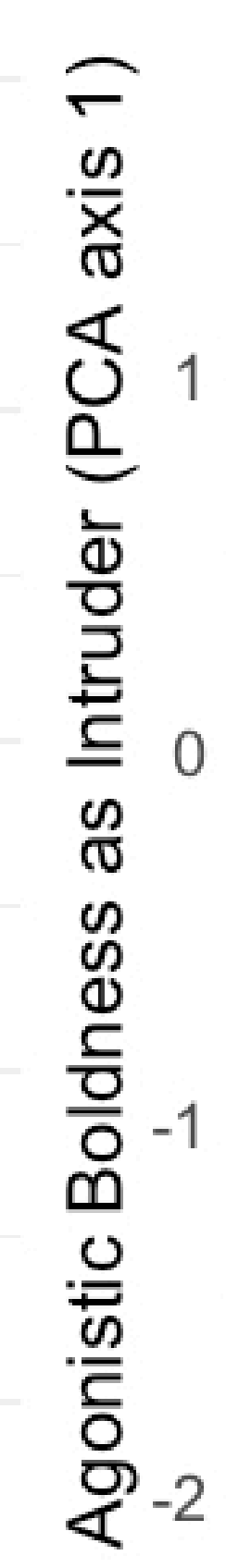
Agonistic Boldness as Resident (PCA axis 1)

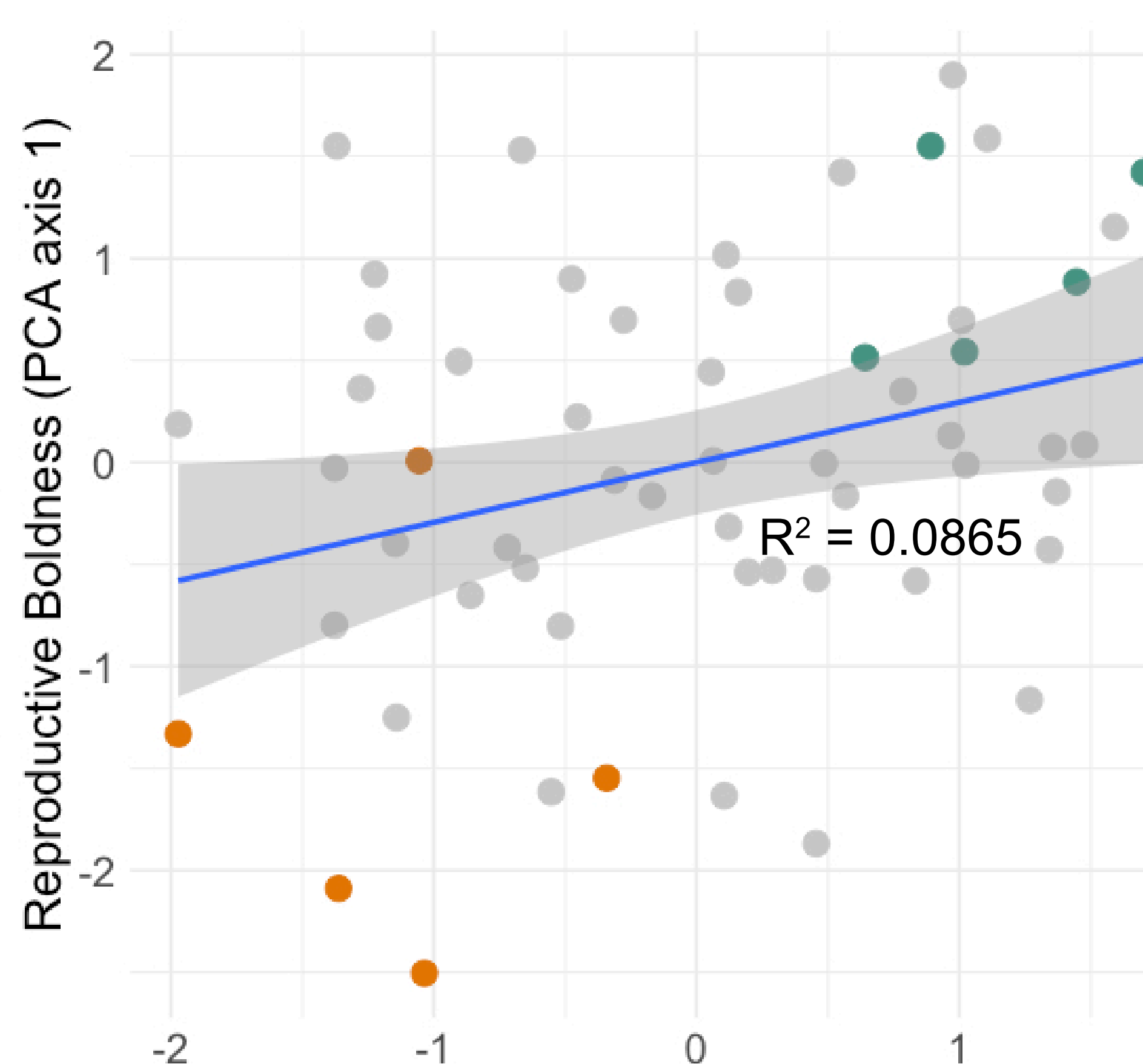

Agonistic Boldness as Intruder (PCA axis 1) 
